\title{
EXPERIÊNCIA E DOCUMENTAÇÃO: É POSSÍVEL ARTICULAR ESTES CONCEITOS?
}

\author{
Cláudia Inês Horn ${ }^{1}$ \\ Jacqueline Silva da Silva ${ }^{2}$
}

\section{Resumo}

Este trabalho apresenta o conceito de experiência fundamentado em Larrosa (2002, 2004) e a sua articulação com a documentação pedagógica. A experiência é o que nos passa, ou o que nos acontece, ou o que nos toca. $\mathrm{O}$ sujeito da experiência seria como um território de passagem, na qual aquilo que passa afeta de algum modo. A documentação pedagógica é vista como uma possibilidade de tornar visível a construção da memória do grupo de crianças em seu contexto escolar, trazendo os conceitos de observação, registro e reflexão como ações estruturantes, inter-relacionadas e inerentes ao processo documentar. $\mathrm{Na}$ medida em que o acontecimento experiência ocorre no contexto escolar, nas relações e interações entre criança-criança e crianças-adultos, a estratégia da documentação pedagógica se faz importante no sentido de revisitar, relembrar, revelar as aprendizagens das crianças.

Palavras-chave: Experiência; Documentação Pedagógica; Educação Infantil; Contexto Escolar; Criança.

A Educação Infantil constitui-se em um tempo e espaço onde as experiências das crianças e adultos são partilhadas, criadas, manifestadas, reproduzidas e ressignificadas durante as interações, as brincadeiras, as conversas e as negociações. Estes momentos constituem uma riqueza na convivência e nas relações, o que possibilita fundamentos e elementos para a documentação, ou seja, são estes acontecimentos - as experiências que podem ser documentados na escola infantil. Quando abordamos a palavra

\footnotetext{
${ }^{1}$ Mestre em Educação/UFRGS. Especialista em Educação Infantil e Pedagoga/Centro Universitário UNIVATES. Coordenadora Pedagógica do Colégio Evangélico Alberto Torres e Docente do Curso de Pedagogia no Centro Universitário UNIVATES - Lajeado. E-mail: clauhorn@ yahoo.com.br ${ }^{2}$ Doutora em Educação/UFRGS. Mestre em Educação/PUCRS. Pedagogia/UNISC. Docente do Curso de Pedagogia e Direito no Centro Universitário UNIVATES/Lajeado. E-mail:jacqueh@univates.br
} 
"experiência", trazemos o conceito de Larrosa (2004), no ensaio Experiência e Paixão, onde o autor afirma que "A experiência é o que nos passa, ou o que nos acontece, ou o que nos toca. Não o que passa ou o que acontece, ou o que toca" (p. 154).

Larrosa (2004), baseando-se em Benjamin, acredita que vivemos num mundo onde a pobreza da experiência é marcante, pois "Nunca se passaram tantas coisas, mas a experiência é cada vez mais rara" (p. 154). O autor expressa quatro pontos para, talvez, justificar a pobreza da experiência na contemporaneidade: primeiro, diz que a informação não deixa lugar para a experiência. $\mathrm{O}$ sujeito da informação sabe muitas coisas, busca informações o tempo todo, sempre quer se manter informado para ser informante, mas é preciso separar o saber da experiência do saber coisas; "uma sociedade constituída sob signo da informação é uma sociedade que a experiência é impossível” (p. 155). Em relação ao segundo ponto, o autor destaca que o excesso de opinião sobre qualquer coisa que o sujeito sente-se informado, cancela as possibilidades de experiência.

Larrosa (2004) sublinha, em terceiro lugar, que a experiência é rara pela falta de tempo. Tudo o que passa, passa através de estímulo fugaz e efêmero, na forma de vivência instantânea, pontual e desconectada, impedindo conexões significativas. Por último, ele enfatiza o excesso de trabalho como algo que destrói a experiência. Conceitua trabalho como toda atividade que deriva da pretensão de conformar o mundo, "tanto o mundo natural quanto o mundo social e humano, tanto a natureza externa quanto a natureza interna segundo seu saber, seu poder e sua vontade" (p. 159).

A experiência requer um gesto de interrupção que, segundo o referido autor, compreende o parar para pensar, olhar, escutar mais devagar, demorar nos detalhes, suspender julgamentos, cultivar a atenção, aprender a lentidão, cultivar o encontro, ter paciência. Acrescenta, ainda, que o sujeito da experiência seria como "um território de passagem, algo como uma superfície de sensibilidades na qual aquilo que passa afeta de algum modo, produz alguns afetos, inscreve algumas marcas, deixa alguns vestígios, alguns efeitos" (p. 160). Dar lugar ao que lhe chega e ao que recebe: "o sujeito da experiência é, sobretudo, o espaço onde tem lugar os acontecimentos” (p. 161). E, assim, a palavra experiência transforma os sujeitos que estão abertos à sua própria transformação.

As razões apresentadas por Larrosa para explicar por que a experiência está cada faz mais rara ou que estamos vivenciando a destruição generalizada da experiência também afeta a vida das crianças nas escolas. O excesso de informação e opinião, o 
tempo e o trabalho são fatores que contribuem para o acontecimento da experiência ser cada vez mais raro. Por acreditar nisso, é que os professores precisam refletir sobre o currículo para a infância, bem como a organização dos tempos e espaços escolares.

Neste sentido, a documentação pedagógica oportuniza importantes contribuições. Partindo do pressuposto de que o ato de documentar é fundamental para tornar os processos vivenciados na escola conhecidos, compreendidos e problematizados em sua essência, é imprescindível definir o que constitui a documentação pedagógica e o processo de documentar nesse artigo.

Cervellati (2005) entende que

A documentação pedagógica institui-se como o registro e a construção da memória de um grupo, tanto individual quanto coletiva. A memória não é passiva, mas construtiva, porque recorda, pesquisa, seleciona, reconstrói e apresenta uma continuidade para o futuro (p. 27-28).

Podemos verificar aqui a relação que Cervellati (2005) faz entre a documentação, a memória e a aprendizagem. A documentação se constitui como um meio indispensável para que os professores possam oportunizar experiências significativas para as crianças. A memória, por sua vez, seria a base da identidade desse grupo de crianças e a continuidade do tempo, sendo que continuidade acompanha o processo de construção do conhecimento das crianças que vai se desenvolvendo no percurso das suas vivências. Nesse sentido, a documentação se faz necessária, uma vez que auxilia os professores a escutar e observar as crianças com que trabalham, possibilitando, assim, a construção de experiências significativas junto a elas, bem como a possibilidade de avaliar a sua prática pedagógica.

Desse modo, quando o professor tem a possibilidade e o desejo de retomar tudo aquilo que foi trabalhado com e para as crianças, ele busca essa memória nos registros ${ }^{3}$ realizados no decorrer de suas práticas diárias. Podemos dizer que a união desses registros é que compõe a documentação pedagógica.

Ressaltamos que a expressão "Documentação Pedagógica" tem origem no projeto educativo das escolas de Reggio Emilia/Itália. Em fevereiro de 2008, tivemos a oportunidade de participar do grupo de estudos nas escolas de Reggio Emilia e percebemos que no projeto educativo todo o professor tem, na sua carga horária de trabalho diário e semanal, um momento reservado e garantido para a documentação,

\footnotetext{
${ }^{3}$ Registro aqui é apresentado como um instrumento metodológico capaz de provocar transformações na prática pedagógica do professor uma vez que lhe permite descrever os seus fazeres e os das crianças e refletir sobre os mesmos, oportunizando-lhe a ressignificação (PROENÇA, 2006).
} 
bem como para a interpretação da documentação individual e coletiva. Isto ocorre em momentos de reunião pedagógica, onde o coletivo de professores analisa a documentação, significando uma estratégia para interpretação do trabalho que se faz e uma possibilidade de refletir sobre os avanços que ocorreram com as crianças.

A documentação pode ser entendida como um processo cooperativo, que auxilia professores a observar, escutar e assim entender melhor as crianças. Na abordagem de Reggio Emilia - Itália, a documentação não é vista como um trabalho isolado e os professores não preocupam-se com os passos finais, com os resultados. Para eles, é fundamental documentar o processo de interação, o processo de criação, e tudo isso é analisado no coletivo de professores, ou seja, a documentação é um importante instrumento de trabalho do professor. A análise e a interpretação da documentação auxilia os professores a esboçar roteiros de ação, uma vez que não é mera coleta de dados para serem arquivados.

Quando dizemos que o que compõe a documentação pedagógica é a união de registros e de materiais, não podemos deixar de enfatizar aqui que a observação, o registro e a reflexão são ações estruturantes, inter-relacionados e inerentes ao processo de documentar já que quando o professor observa e registra o percurso das vivências das crianças - suas aprendizagens - a partir desse registro, ele faz uma reflexão sobre as suas escolhas frente às propostas que oportunizou às crianças e, consequentemente, torna a sua prática mais significativa para as crianças e para ele próprio.

"A documentação é o início de tudo, pois o indivíduo, ao registrar e analisar suas experiências, pode qualificar a análise e a reflexão" (BARBOSA E HORN, 2008, p. 119). O registro é uma maneira constante de o professor refletir sobre a sua prática e encaminhar estratégias para alcançar novos objetivos e ter autoria sobre suas ideias, refletir e produzir para si mesmo condições de fazer o seu percurso investigativo. Ele colabora com os professores dando-lhes a oportunidade de capturarem os acontecimentos e retê-los no tempo, para que possam mais tarde utilizá-lo como fonte de leituras, análises, reflexões e interpretações.

Junqueira Filho (2007) define assim o registro:

(...) registrar é ir a um encontro marcado consigo mesmo; é recobrar em parte o que aconteceu no encontro com o outro; é selecionar, hierarquizar, jogar fora, encontrar lugar, sentir falta de algo e não conseguir encontrar, sentir falta de algo que nunca teve e colocar-se como objetivo providenciar, priorizar, conseguir, conquistar... É arrumar continuamente a casa para o próprio bem-estar e aconchego e para apresentar-se e receber bem o outro que chega todo dia para nos encontrar (p. 11). 
Em relação à observação, Freire (1996) afirma:

\begin{abstract}
Observar uma situação pedagógica é olhá-la, fitá-la, mirá-la, admirá-la, para ser iluminada por ela (...) não é vigiá-la mas sim, fazer vigília por ela, isto é, estar e permanecer acordado por ela, na cumplicidade da construção do projeto, na cumplicidade pedagógica (p. 14).
\end{abstract}

As observações, transformadas em registros que passam a fazer parte da documentação pedagógica também podem ser utilizadas como "instrumento para reflexão", ${ }^{4}$, permitindo ao professor refletir não somente sobre o que acontece entre as crianças, mas também sobre si mesmo, como ele vem se constituindo como professor. Desse modo, a documentação pedagógica oportuniza a reflexão do sentido da própria experiência, favorecendo, assim, de certo modo, a formação permanente do professor. Ela pode ser considerada, nesse caso, como "espelho da alma", ${ }^{,}$uma vez que possibilita ao professor a apropriação do seu fazer pedagógico, tornando-se fonte de consulta e de autorreferência e, ainda, fonte de teorização da própria prática, servindo como instrumento de sua autonomia intelectual, mostrando-lhe como tem se construído como profissional: "E quanto maior for a nossa consciência das nossas práticas pedagógicas, maior será a nossa possibilidade de mudar" (DAHLBERG, MOSS, PENCE, 2003, p. 200).

Os registros realizados pelas crianças também são muito importantes. Envolver as crianças no que diz respeito ao fazer registros pode ser uma forma de se comprometerem ainda mais com experiências, tornando-se, desse modo, responsáveis perante si, assim como perante a turma em que se encontram inseridas. Nesse sentido, Vasconcelos (1997) corrobora dizendo:

Penso que é muito importante que as crianças aprendam a registrar as coisas. Fazer é importante, mas também o é refletir sobre aquilo que cada um está a fazer... antecipar aquilo que cada um quer fazer. Primeiro têm de pensar no que querem fazer (p. 156).

\footnotetext{
${ }^{4}$ Expressão utilizada por Dahlberg, Moss, Pence (2003) no sentido de pensar sobre o trabalho do professor, sobre sua atuação como profissional.

${ }^{5}$ Expressão utilizada por Proença (2007) ao se referir à documentação pedagógica como um reflexo de tudo aquilo que o professor realiza.
} 
Diríamos que refletir é uma exigência quando o trabalho envolve a documentação pedagógica, quando queremos realmente desenvolver uma prática pedagógica que tenha sentido para as crianças e para nós mesmos.

De acordo com Mazzoli (2005),

\begin{abstract}
Entende-se a documentação como um espaço para o pensar, como possibilidade para reapropriar-se do valor pedagógico que deve orientar o próprio projeto educativo e reconsiderá-lo à luz do cotidiano, pois torna-se um instrumento importante da autoformação profissional (p. 39).
\end{abstract}

As escolhas que fazemos para mostrar o que acontece aos outros e a nós mesmos muitas vezes estão envolvidas por concepções e, quando as documentamos, "somos coconstrutores das vidas das crianças e incorporamos nossos pensamentos implícitos do que consideramos serem ações valiosas em uma prática pedagógica" (DAHLBERG, MOSS, PENCE, 2003).

Como documentar? Gandini e Goldhaber (2002) afirmam:

Quando executamos as tarefas preparatórias para esse momento, estamos começando a pensar no que observamos e - entre outras experiências conscientizadoras - estamos percebendo com maior clareza a nossa forma de nos relacionarmos com as crianças (p. 154).

Podemos dizer aqui que o resultado estético ${ }^{6}$ e de qualidade da documentação pedagógica também deverá ser uma preocupação do professor, uma vez que a documentação poderá estimular outras pessoas a conhecerem o trabalho. Por isso, um material com resultado estético e de qualidade.

Lino (1996), ao ressaltar a importância do envolvimento das famílias com as vivências escolares das crianças, traz à tona o direito das famílias de estarem informadas sobre o processo de desenvolvimento dos seus filhos, bem como de participarem de toda a ação educativa. Desse modo, o interesse dos pais pelos trabalhos das crianças lhes permite aprofundar os conhecimentos das aprendizagens das mesmas, assim como dos seus interesses.

Sabemos que esse interesse deveria fazer parte do cotidiano da vida desses pais, mas sabemos também que nem sempre isso acontece, transformando-se muitas vezes

\footnotetext{
${ }^{6}$ Estético, conforme Hoyuelos (2004), no sentido de dar importância a cada detalhe, pela preocupação em fazer com que os registros possam ser compreendidos pelos outros e que possam ser expostos de forma atrativa.
} 
em uma tarefa difícil para os professores conseguirem o envolvimento deles nas questões escolares.

Ainda, para o mesmo autor,

Os professores procuram a confiança dos pais ao documentar os trabalhos das crianças de forma que eles saibam detalhadamente o que fazem na escola. $\mathrm{E}$ os trabalhos realizados pelas crianças tornam-se a base para estabelecer o diálogo entre eles (LINO, 1996, p. 103).

Acreditamos que a documentação pedagógica contribui como uma estratégia para, além de buscar o envolvimento com as famílias, permite preservar as memórias no tempo e no espaço em que aconteceram, dar visibilidade às experiências vivenciadas pelas crianças, possibilitando ao professor e às próprias crianças revisitar, reconstruir, ressignificar estes momentos.

A documentação permite escutar e ver novamente aquilo que já aconteceu, é relembrar e valorizar os acontecimentos significativos nas interações escolares. Poderíamos dizer que, através da documentação, o parar para pensar, olhar e escutar mais devagar, demorar nos detalhes, suspender julgamento, cultivar a atenção, pode se tornar uma prática nas escolas.

Assim a documentação produzida na escola pode contribuir na valorização do acontecimento experiência, na medida em que o professor analisa o material coletado, relembra as vivencias entre criança-criança e criança-adulto, reflete sobre as interações, as relações e as aprendizagens, buscando novas propostas de trabalho e situações para serem oferecidas às crianças.

Até aqui, poderíamos nos questionar: Como a documentação pedagógica pode revelar o acontecimento experiência? Ou... é possível revelar as experiências das crianças? No ensaio "Sobre leitura, experiência e formação", Larrosa (2004) colabora, dizendo que:

A experiência seria precisamente o indeterminado da vida, esse passar do que nos passa quando não sabemos o que nos passa, essas afecções que nos levam a questionar o que já sabemos, o que já queremos, tudo o que se deixa submeter sem dificuldades a medida do que já somos (LARROSA, 2004, p. $331)$

Acreditamos que a documentação constitui uma excelente oportunidade pedagógica para o professor escutar, ver e visitar novamente os acontecimentos dos quais foram protagonistas as crianças e os adultos. Conforme aponta Dewey (1971) é preciso garantir a reconstrução contínua da experiência, e nessa perspectiva a documentação pode ser uma estratégia para reconstruir as experiências, pois ela emerge 
do cotidiano da escola de Educação Infantil que valoriza (ou deveria sempre valorizar) as relações e interações entre os sujeitos envolvidos neste contexto.

A documentação é uma possibilidade de transformar a experiência individual em novas possibilidades de observação, registro e reflexão, trazendo à tona as situações que tenhamos visualizado como significativas entre as crianças. Nesse sentido, Larrosa (2002) corrobora dizendo:

\begin{abstract}
O acontecimento é comum, mas a experiência é para cada qual sua, singular e de alguma maneira impossível de ser repetida. O saber da experiência é um saber que não pode separar-se do indivíduo concreto em quem encarna. Não está, como o conhecimento científico, fora de nós, mas somente tem sentido no modo como configura uma personalidade, um caráter, uma sensibilidade ou, em definitivo, uma forma humana singular de estar no mundo, que é por sua vez uma ética (um modo de conduzir-se) e uma estética (um estilo). Por isso, também o saber da experiência não pode beneficiar-se de qualquer alforria, quer dizer, ninguém pode aprender da experiência de outro, a menos que essa experiência seja de algum modo revivida e tornada própria.
\end{abstract}

Podemos verificar que todo o trabalho da documentação, considerando a experiência das crianças no contexto escolar, será possível na medida em que o professor perceber a criança como um sujeito que experimenta o mundo e que se sente parte deste mundo. Sujeito esse, com potencialidades para criar, questionar, expressar-se e comunicar-se. De acordo com Rinaldi (in GANDINI e EDWARDS, 1999), a criança apresenta um competente sistema de habilidades, estratégias de aprendizagem e formas de organizar seus relacionamentos, ou seja, ela é vista como um ser competente, ativo e crítico. As crianças não são vistas simplesmente como sujeitos com necessidades, pois, além de receber, elas querem também oferecer.

Compactuamos com essa concepção de criança, e, partindo dessa perspectiva, o professor ao aproximar-se das mesmas, utiliza a observação e a escuta sensível (Barbier, 1993) para entender melhor como ela lida com as situações do cotidiano, como enfrenta e resolve as situações de conflito entre pares, quais são as suas formas de expressão, quais as linguagens que se utiliza para interpretar o mundo, os outros e a si mesma, para dar sentido às suas experiências.

Diante do que foi apresentado, acreditamos que o trabalho com a documentação pedagógica caracteriza-se por um instrumento que sustenta a ação educativa e revela as experiências das crianças no contexto escolar, onde o professor vive a documentação pedagógica como ocasião de conhecimento, de ampliação de saberes e de edificação da prática pedagógica. 


\section{ESPERIENZA E DOCUMENTAZIONE: E 'POSSIBILE ESPRIMERE QUESTI COCETTI?}

\section{Riassunto}

L' esperienza è quello che passiamo, oppure quello che ci succede, o quello che ci colpisce. Il soggetto dell' esperienza sarebbe come un territorio di passaggio, nel quale quello che passa colpisce in alcun modo. La documentazione pedagogica è veduta come una possibilità di diventare visibile la costruzione della memoria del gruppo di bambini nel suo contesto scolastico, portando i concetti di osservazione, registro e riflessione come azioni struturanti, frarelazionate ed inerenti al processo documentale. Pare passo che l'avvenimento esperienza succede nel contesto scolastico, ne rapporti e interazioni tra bambini-bambini e bambini-adulti, la strategia della documentazione pedagogica si fa importante nel senso di rivisitare, ricordare, rivelare gli apprendimenti dei bambini.

Parole chiave: Esperienza; Documentazione Pedagogica; Scuola Materna; Contesto Scolastico; Bambini.

\section{Referências}

BARBIER, René. A escuta sensível em educação. Cadernos Anped, Porto Alegre, n 5, p. 187-286, 1993.

BARBOSA, Maria Carmen Silveira; HORN, Maria da Graça Souza. Projetos pedagógicos na educação infantil. Porto Alegre: Artmed, 2008.

BENJAMIN, W. Obras escolhidas 2. Rua de Mão Única. São Paulo: Editora Brasiliense, 2004. 
CERVELLATI, Mauro. Teoria e pratica della documentazione nella progettazione educativa. IN: MAZZOLI, Franca. Documentare per documentare. Experienze di documentazione nei servizi educativi dell'Emilia-Romagna. Regione-Emilia Romagna: Progetto Grafico Ad. Opera srl, 2005.

DAHLBERG, G., MOSS, P., PENCE, A. Documentação pedagógica: Uma Prática para a Reflexão e para a Democracia. IN: Qualidade na educação da primeira infância: perspectivas pós-modernas. Porto Alegre: Artmed, 2003.

DEWEY, J. Experiência e educação. São Paulo: Companhia Editora Nacional, 1971.

FREIRE, Madalena. Pedagogia da autonomia: saberes necessários à prática educativa. São Paulo: Paz e Terra, 1996.

GANDINI, L.; GOLDHABER, J. Duas reflexões sobre a documentação. IN: Bambini: a abordagem italiana à educação infantil. POA: Artmed, 2002.

HOYUELOS, Alfredo. La Estetica En El Pensamiento Y Obra De Loris Malaguzzi. 2006 São Paulo: Cortez, 2007.

JUNQUEIRA FILHO, Gabriel de Andrade. Quando as imagens não falam mais que as palavras. Revista Pátio Educação Infantil. Ano IV. N²12. Nov 2006/Fev 2007.

LARROSA, Jorge. Notas sobre a experiência e o saber da experiência. Revista Brasileira de Educação, nº.19 Rio de Janeiro jan./abr. 2002

LARROSA, Jorge. Linguagem e Educação depois de Babel. Belo Horizonte: Autêntica, 2004.

LINO, Dalila. O Projecto de reggio Emilia: uma apresentação. Princípios básicos do modelo. IN: FORMOSINHO, Júlia Oliveira (org.). Modelos curriculares para a educação de infância. Portugal: Porto Editora, 1996.

MAZZOLI, Franca. Documentare per documentare. Experienze di documentazione nei servizi educativi dell'Emilia-Romagna. Regione-Emilia Romagna: Progetto Grafico Ad. Opera srl, 2005.

PROENÇA, M. A. Registro reflexivo e autoformação. Revista Pátio Educação Infantil, ano IV, n. 12, p. 13-. 15, nov. 2006

RINALDI, Carlina. O Currículo Emergente e o Construtivismo Social. In: EDWARDS, Carolyn. As cem linguagens da criança: a abordagem de Reggio Emilia na Educação da primeira infância. Porto Alegre: Editora Artes Médicas Sul Ltda., 1999.

VASCONCELOS, Teresa M. Ao redor da mesa grande. Porto: Porto Editora, 1997.

Data de recebimento: $18 / 10 / 2011$

Data de aceite: $21 / 11 / 2011$ 